\title{
Intravitreal triamcinolone with transpupillary therapy for subfoveal choroidal neovascularization in age related macular degeneration. A randomized controlled pilot study [ISRCTN74 I 23635]
}

\author{
Ricardo Agurto-Rivera*1, Jose Diaz-Rubio ${ }^{1}$, Luis Torres-Bernal1, \\ Tamer A Macky², Juner Colina-Luquez ${ }^{1}$, Gabriela Papa-Oliva1, \\ Rama D Jager ${ }^{3}$, Susana Martinez-Jardon ${ }^{1}$, Jans Fromow-Guerra ${ }^{1}$ and \\ Hugo Quiroz-Mercado ${ }^{1}$
}

\begin{abstract}
Address: ${ }^{1}$ Retina Service, Asociación Para Evitar la Ceguera (APEC), Mexico City, Mexico, ${ }^{2}$ Department of Ophthalmology, Kasr El Aini Hospital, Cairo University, Cairo, Egypt and ${ }^{3}$ Department of Ophthalmology, Harvard Medical School, Boston, Massachusetts, USA

Email: Ricardo Agurto-Rivera* - ricardo_agurto@yahoo.com; Jose Diaz-Rubio - retinamex@yahoo.com; Luis Torres-

Bernal - retinamex@yahoo.com; Tamer A Macky - retinamex@yahoo.com; Juner Colina-Luquez - retinamex@yahoo.com; Gabriela PapaOliva - retinamex@yahoo.com; Rama D Jager - retinamex@yahoo.com; Susana Martinez-Jardon - retinamex@yahoo.com; Jans FromowGuerra - retinamex@yahoo.com; Hugo Quiroz-Mercado - retinamex@yahoo.com

* Corresponding author
\end{abstract}

Published: 25 November 2005

BMC Ophthalmology 2005, 5:27 doi:10.1 I86/147|-24I5-5-27

This article is available from: http://www.biomedcentral.com/I47I-24I5/5/27

(c) 2005 Agurto-Rivera et al; licensee BioMed Central Ltd.

This is an Open Access article distributed under the terms of the Creative Commons Attribution License (http://creativecommons.org/licenses/by/2.0), which permits unrestricted use, distribution, and reproduction in any medium, provided the original work is properly cited.

\begin{abstract}
Background: To assess the effect of intravitreal triamcinolone acetonide (iTA) as an adjunctive treatment to transpupillary therapy (TTT) for new subfoveal choroidal neovascular membranes (CNV) in age-related macular degeneration (AMD).

Methods: This prospective randomized controlled pilot study comprised 26 patients scheduled to receive TTT, due to either absent indications for photodynamic therapy or financial issues. Patients were assigned into; Group A $(n=14)$ received TTT alone and Group $B(n=12)$ received iTA $(4 \mathrm{mg})$ followed by TTT within one week. Follow ups were at 2 weeks, and I, 3 and 6 months for; best-corrected visual acuity (BCVA) by ETDRS chart at 4 meters, intraocular pressures (IOP), fluorescein angiography (FAG), and central foveal thickness by optical coherence tomography (OCT).

Results: All 26 patients completed 6 months of follow ups. The average age for both groups was 74 years. Occult CNV formed $64 \%$ and $41 \%$; classis/predominately classic $21 \%$ and $16.6 \%$; and minimally classic $15 \%$ and $42.4 \%$ of group $A$ and $B$ respectively. At baseline; the mean BCVA was 0.045 for group $A$ and 0.04 for group B; mean CNV size was 6.15 disc diameter (DD) and 2.44 DD; mean OCT foveal thickness was 513 um and $41 \mathrm{I}$ um for group $A$ and $B$ respectively with no statistical differences $(P=0.8,0.07$, and 0.19$)$. At six months the proportion of patients gained $\geq I$ lines was $14 \%$ and $25 \%(P=0.136)$ and stabilization was $86 \%$ and $66 \%(P=0.336)$; the mean size of the CNV was $5.63 \mathrm{DD}$ and $2.67 \mathrm{DD}(P=0.162)$; rate of $C N V$ closure was $64 \%$ and $83 \%(P=0.275)$; and the mean OCT central foveal thickness was 516.36 um and 453.67 um $(P=0.34 I)$, for group $A$ and $B$ respectively.

Conclusion: The use of iTA as an adjunctive to TTT for new subfoveal CNV in AMD showed a tendency towards better functional results. However due to the small sample size of the study a statistically significant results could not be reached.
\end{abstract}




\section{Background}

Age-related macular degeneration (AMD) is one of the leading causes of blindness in the western world; with the most common cause of visual loss is the formation of choroidal neovascularization (CNV) [1]. Laser photocoagulation has been proven to be more effective than the natural history of the disease process in both extra- and juxtafoveal CNV $[2,3]$. Currently, photodynamic therapy (PDT) with verteporfin and laser photocoagulation are the only proven therapies for the subfoveal CNV [4-8].

PDT has been proven beneficial for patients with both predominately classic $\mathrm{CNV}$ and with some benefits for occult with no classic CNV [4,6]. A retrospective review of 1000 consecutive patients with CNV in AMD showed that $17.1 \%$ had predominantly classic CNV [9]. In addition, analysis has shown that the treatment has minimal cost effectiveness, which is principally due to the high cost of the drug, the need of many retreatments, and the continuing visual decline that most patients experience even with re-treatments [10].

Transpupillary therapy (TTT) is a technique in which heat is delivered to the choroid and retinal pigment epithelium through the pupil using an 810-nm infrared diode laser. The diode laser has theoretical advantages over other wavelengths of light because there is little absorption in the xanthophyll layer and thus damage to the nerve fiber layer is minimized. Also, it is poorly absorbed by hemoglobin allowing an improved ability to treat through preretinal and subretinal hemorrhage [11]. The wavelength of the diode laser is mainly absorbed by melanin at the level of the choroid and retinal pigment epithelium, enabling treatment of choroidal lesions [12]. TTT is also significantly less expensive than PDT. It has been used to treat choroidal melanomas, and in preliminary trials to treat both classic and occult subfoveal CNV [13-17].

There is evidence suggesting that steroids may have a beneficial effect in patients with CNV. Eyes with CNV have histopathologic evidence of inflammation, and neovascularization is a frequent component of inflammatory processes [18-20]. Histopathological examination of CNV complexes has shown the presence of inflammatory cells [18-20]. In addition the amount of vascular endothelial growth factor (VEGF), the major cytokines involved in initiating angiogenesis, has been shown to be proportional to the amount of inflammatory cells present [21]. Corticosteroids also have in addition a direct antiangiogenic effects [22-25]. Triamcinolone acetonide and other steroids have been shown to be effective in inhibiting neovascularization in animal models [26,27]. Several clinical studies have shown an apparent beneficial effect where treated patients appeared to have a favorable effect on vis- ual acuity and fundus appearance, although a significant proportion of patients still lost vision [28-30].

It may be possible to treat patients with $\mathrm{CNV}$ with TTT plus iTA, to combine the immediate effect of TTT with the longer-lasting, anti-inflammatory and possibly synergistic effect of intraocular triamcinolone. To help investigate this possibility we started a randomized controlled pilot study of combined TTT with iTA for CNV in patients with AMD.

\section{Methods}

Although a randomized, multicenter, prospective, placebo-controlled trial (TTT4CNV, preliminary results, ARVO 2005) is underway to investigate the value of TTT in the treatment of occult subfoveal CNV, we did not find any report in a medline search that evaluates the effect of intravitreal triamcinolone with TTT for subfoveal CNV. Considering recent reports that demonstrate beneficial effects when triamcinolone is associated to PDT, we decided to conduct a prospective randomized nonmasked clinical study of combined TTT with iTA in patients with $\mathrm{CNV}$ secondary to AMD.

Approval for the study was obtained from the hospital's ethical committee which is in compliance with the Helsinki Declaration. All patients received a thorough explanation of the study design and aims, and were provided with written informed consent. Patients were seen at Asociación Para Evitar la Ceguera en Mexico, "Dr. Luis Sanchez Bulnes Hospital", Mexico City, Mexico. All patients had a baseline evaluation for the following:

- Best-Corrected Visual Acuity (BCVA) that was evaluated using an ETDRS chart, measured with refraction obtained at the beginning of the study and recorded as a decimal equivalent value. Special careful was taken to avoid extrafoveal fixation.

- Slit-lamp biomicroscopy

- Indirect ophthalmoscopy

- Flourescein angiography (FAG)

- Optical Coherence Tomography (OCT) measurement of central foveal thickness.

Eligibility criteria includes: 55 years or older, new CNV under the geometeric center of the fovea, and VA of $<0.20$. No restriction to the type of the membrane (classic, predominately classic, or occult) was made. The patient had to have a clear media and the ability and willingness to understand the informed consent. Patients were excluded if they had received previous treatment, have any condi- 

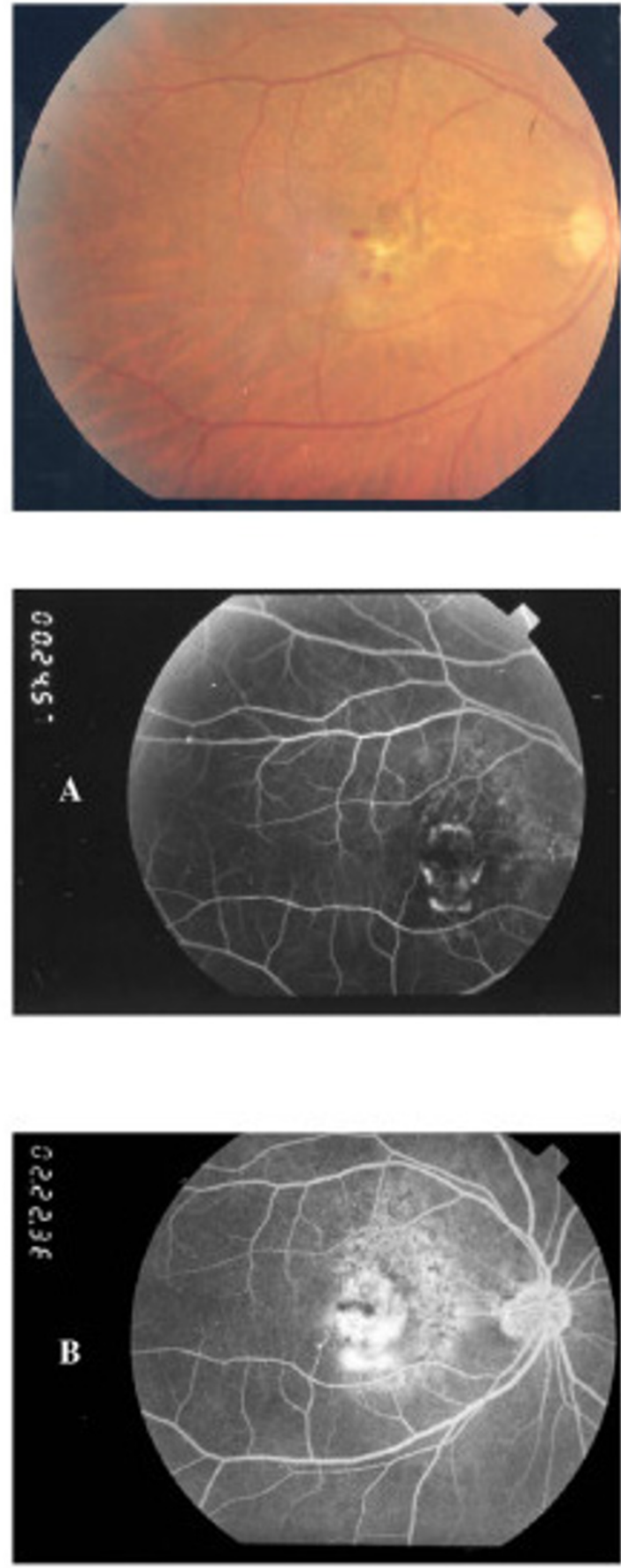

\section{Figure I}

A 65 year old patient with visual acuity of $1 / 10$ in right eye that developed visual lost three months earlier. Color photograph shows a CNV with a small hemorrhage and sub retinal fluid. Fluorescein angiogram shows A: Early RPE defects above and below the foveal center. Later B: shows late dye leakage indication occult CNV. tion other than AMD to account for the CNV or refuse follow up. Patients could not have pre-existing atrophy of the fovea or a rip of the retinal pigment epithelium (RPE). Patients were also excluded if they were using corticosteroids. They could not have any disease that would interefere with the treatment, increased risk of side effects, or been confused with side effects of the treatment (as anticoagulant treatment, hepatitis, prophyria, uncontrolled glaucoma, or sensitivity ot the drug or the flourescein dye used in the trial). Only one eye per patient was entered in the study.

Once the patients accepted to be part of the study, were randomly assigned by an unmasked investigator (RA) using a random number table, to one of two groups: Group A received transpupillary thermotherapy (TTT) alone, and Group B received TTT within a week of intravitreal triamcinolone acetonide injection (iTA). Same investigator (RA) treated the patients, knowing the assigned group before to apply TTT or inject iTA.

\section{Transpupillary therapy}

Transpupillary thermotherapy was delivered through a slit lamp using a modified infrared diode laser at $810 \mathrm{~nm}$ with an adjustable beam width of $1.2 \mathrm{~mm}, 2.0 \mathrm{~mm}, 3.0$ $\mathrm{mm}$ and $4.3 \mathrm{~mm}$ (Iris Medical Instruments, Mountain View, CA). The treatment parameter was adjusted according to the CNV type and size. Topical $0.5 \%$ proparacaine was applied before placement of a three mirror Goldmann lens coated for use with the diode laser. Continues observation through the slit lamp ensured fixation. Treatment was initiated with one spot for 60 seconds' duration at a power setting ranging between 360 and $880 \mathrm{~mW}$ such that no visible change or a barely detectable light-gray appearance to the lesion was present at the end of the treatment. Power settings was proportional to the spot size with larger spots requiring higher energy levels. In general, for a 2-mm spot size, the initial power level was between $360 \mathrm{~mW}$ and $700 \mathrm{~mW}$. The spot size was adjusted to be 500 um larger than the membranes' greater diameter, if the CNV is larger than $4300 \mathrm{um}$, then overlapping spots were used. If any retinal whitening was observed or patient felt any pain, the power of the laser was decreased by $100 \mathrm{~mW}$. Treatment was re-initiated and if retinal whitening continued to be observed, the power setting was again decreased by $100 \mathrm{~mW}$. Care was taken to ensure that the entire lesion border was covered with treatment beam.

\section{Intravitreal triamcinolone injection}

Intravitreal triamcinolone acetonide were given as follows: patients received several drops of topical proparacaine and one drop of Betadine 5\% solution (Purdue Pharma, L.P., Stamford, CT). They were given then topical flouroquinolone drops once every 5 minutes for $30 \mathrm{~min}$ utes. A wire speculum was inserted in the eye. The patient 

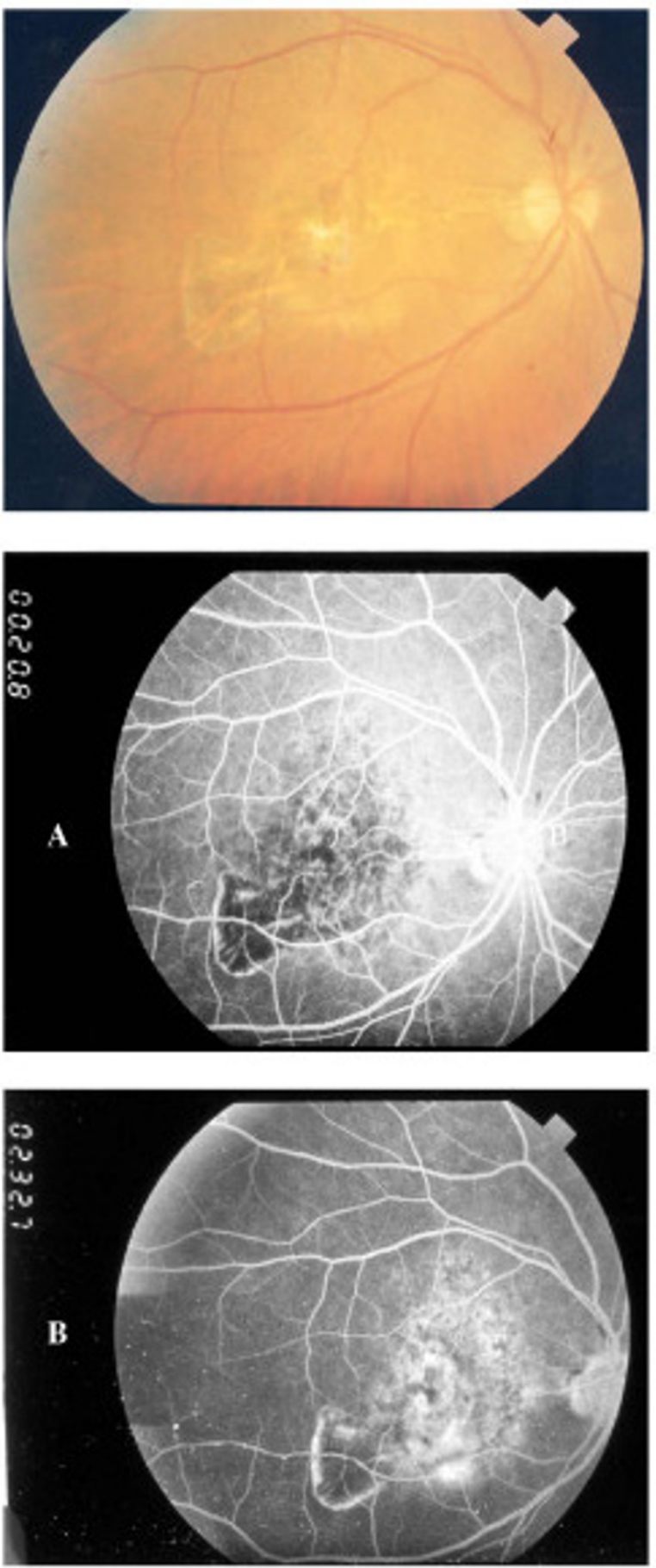

\section{Figure 2}

Patient in figure I, four months after TTT and iTA. Color photograph shows absence of sub retinal fluid and hemorrhage. Fluorescein angiography shows in (A) a large area of RPE and choroidal atrophy with (B) late staining of the enlarged chorioretinal scar after treatment with no evidence of dye leakage. reclined slightly and was instructed to look up. An injection of 0.1 cc triamcinolone (Kenalog $40 \mathrm{mg} / \mathrm{ml}$, Bristol Myers Squibb, New York, NY) was given at the 6-o'clock postion 3.5 to $4 \mathrm{~mm}$ posterior to the limbus using a 27 gauge needle. During the injection the needle was inserted 3 to $4 \mathrm{~mm}$ into the eye. The intraocular pressure was measured 5 minutes afterwards. If the IOP exceeded 24 $\mathrm{mmHg}$ at any time during follow ups, patients were given topical medications. If IOP exceeds $40 \mathrm{mmHg}$ an anterior chamber paracentesis using a 30-gauge needle to remove $0.1 \mathrm{cc}$ of aqueous humor was performed.

\section{Follow ups}

Patients were give topical antibiotics to use four times per day for one week. Patients were seen in follow ups at 2 weeks, and 1,3 and 6 months after the treament. At each follow up visit, they had BCVA measurement, slit lamp biomicroscopy, intraocular pressure measurement (IOP), and indirect ophthalmoloscopy. FAG, and OCT measurement of foveal center were done at 3 and 6 months. Retreatment was performed using the same protocol if there was no change in subretinal elevation by clinical examination and OCT, together with persistent leakage on FAG at 3 and 6 months.

\section{Outcome measures}

Primary outcomes were BCVA, CNV size and rate of closure, and OCT measurements at the foveal center. Main secondary outcome was retreatment rates.

\section{Results}

There were 26 eyes of 26 patients enrolled in our study. The mean age was 74 years for both groups with no statistical difference in the age of the patients or other demographic data (Table 1) between the two groups. Baseline mean BCVA were 0.045 and 0.04 in groups A and B respectively, with no statistical significant difference $(\mathrm{P}=$ 0.885 Mann-Whitney). In group A there were $64 \%(9 / 14)$ occult CNV, $21 \%(4 / 14)$ classic/predominately classic $\mathrm{CNV}$, and $15 \%(1 / 14)$ minimally classic CNV. In group B there were $41 \%$ (5/12) occult CNV, $16.6 \%$ (2/12) classic/ predominately classic CNV and $16.6 \%(2 / 12)$ minimally classic CNV, 3 patients was undetermined. The breakdown of the type of the CNV showed no statistical difference between both groups ( $\mathrm{P}=0.095$ Mann-Whitney). The mean CNV size at baseline was 6.15 disc diameter (DD) and 2.44 DD for group A and $\mathrm{B}$ respectively ( $\mathrm{P}=$ 0.075 Mann-Whitney). The mean OCT foveal thickness was $513 \mathrm{um}$ and $411 \mathrm{um}$ for group A and B respectively at baseline with no statistical significant different $(\mathrm{P}=0.190$ Mann-Whitney).

\section{Six-month data}

The six months follow up was available for all 26 patients. Media BCVA was 0.045 for both groups. The proportion 
of patients gained $\geq 1$ lines was $14 \%$ (1/14) and 25\% (2/ 12) for group $A$ and $B$ respectively $(P=0.336$ Wilcoxon test), and stabilized in $86 \%(12 / 14)$ and $66 \%(8 / 12)$ of patients in group A and $B$ respectively $(P=0.26$ Wilcoxon test) both of which were not statistically significant. The mean size of the $\mathrm{CNV}$ was 5.63 DD and 2.67 DD for patients in group $A$ and $B$ respectively $(P=0.162$ MannWhitney). Rate of CNV closure was 64\% (9/14) and 83\% $(10 / 12)$ for group A and B respectively at six months ( $\mathrm{P}=$ 0.275 Chi Square). The proportion of patients with subretinal fluids was $60 \%$ and $50 \%$ with the mean OCT central foveal thickness was $516.36 \mathrm{um}$ and $453.67 \mathrm{um}$, for groups A and B respectively ( $\mathrm{P}=0.341$ Mann-Whitney). All the above mentioned data were not statistically significant when compared to baseline and between both groups.

Occult CNV had more lines gain, where 60\% (3/5) of patients receiving iTA showed lines gain compared with $22 \%(2 / 9)$ of patients not receiving iTA. Also patients with occult CNV had a relatively better response to iTA than classic membranes where $66 \%$ of patients without iTA showed lines gain compared with $80 \%$ of patients with iTA. The retreatments rate was $36 \%$ and $17 \%$ for groups A and $\mathrm{B}$ respectively $(\mathrm{P}=0.175$ Chi Square $)$.

\section{Complications}

No patient had evidence of endophthalmitis at any time point. An increase in intraocular pressure beyond 23 mmHg was experienced in 2 patients in group $\mathrm{B}$, who did not have previous glaucoma. Intraocular pressure was controlled with topical medication using beta blockers in both patients. Mean IOP at baseline was 15.1 and 16.3 $\mathrm{mmHg}$, and at six months was 15.0 and $16.3 \mathrm{mmHg}$ for groups A and B respectively. However two weeks after triamcinolone injection the mean IOP in group B was 17.9 $\mathrm{mm} \mathrm{Hg}$. The lens status was not graded in this study by a formalized method such as the Lens Opacities Classification System (LOCS II) [31]. However progression of nuclear sclerosis was not seen in any patient.

\section{Discussion}

This single-center prospective comparative randomized pilot study examined the use of combined TTT with iTA for the treatment of $\mathrm{CNV}$ secondary to AMD. We found that although there was no statistical significant difference in the functional result between both groups there was a trend in favor of the combined TTT with iTA. Patients receiving iTA with TTT had more line gains at six months, than those that did not receive iTA. In addition there was less retreatment in patients in the iTA group, than in the other group. However the anatomical results were clinically and statistically insignificant, in terms of the final size of the CNV, and OCT central foveal thickness.
Although exudative AMD is the leading cause of visual loss in patients above 60 years in western countries, conventional PDT with verteporfin can be given as a treatment in a minority of those with the disease [1]. In addition patients with $\mathrm{CNV}$ require multiple retreatments. The proportion requiring retreatments at the first 3month interval is $90.8 \%$ for the TAP study and $68.9 \%$ for the VIP study [4-6]. In addition, PDT has minimal cost effectiveness as shown by previous studies [10]. TTT on the other hand is significantly less expensive than PDT and its energy penetrate deep to the choroid and RPE with minimal absorption by neurosensorial retina. The energy is eliminated like heat causing an elevation of local temperature (15-20 degree Celsius) inducing apoptosis with thermal inhibition of angiogenesis and vascular thrombosis $[14,15]$. TTT in preliminary trials showed benefits in treating both classic and occult subfoveal CNV [14-17].

There are several possible reasons to combine TTT with iTA. Choroidal neovascularization have other constituents such as inflammatory cells, and other signs of inflammation that might not benefit from the short term angiogenic effect of TTT [18-20]. Corticosteroids have a direct antiangiogenic effects [22-25]. And have been shown to be effective in inhibiting neovascularization in animal models [26-28]. Steroids can modulate the production of and reduce the permeability increased by VEGF. These secondary effects would not be expected to occur with TTT alone. Intravitreal TA persists in the vitreous cavity which extends the duration of treatment against the neovascular complex [32,33]. Several clinical studies have shown an apparent beneficial effect where treated patients appeared to have a favorable effect on visual acuity and fundus appearance, although a significant proportion of patients still lost vision [29-31].

In his pilot study, Reichel et al had 16 patients with occult subfoveal CNV treated with TTT with 12 months of follow ups [14]. Visual acuity improved 2 or more lines in $19 \%$, stabilized in 56\%, the exudation decreased in $94 \%$ of patients, and $19 \%$ of cases had to be re-treated. Other authors described improvements of 2 or more lines between 12.4 to $30 \%$ of cases, and VA stabilization between 40 to $43 \%$, exudation reduction was around $75 \%$ and approximately $25 \%$ of patients required re-treatment [15-19]. In our study we obtained $14 \%$ and $25 \%$ VA improvement of one or more lines for group $\mathrm{A}$ and $\mathrm{B}$ respectively. However the little number of patients did not permit us to establish a statistical difference between groups, but our results are comparable to those reported in the literature. Also results of stabilization of VA, which was $86 \%$ and $66.6 \%$ of patients in group A and B respectively, was consistent with previous reports. We believed that these results must to be considered in the context of patients with very low VA, so excessive diminution was 
difficult, also many patients were considered out of therapeutical limits due to big size of membrane and bad VA, even though we could obtain improvement from baseline visual acuity.

Complications arising from this treatment may be expected to include all of those that could occur from TTT therapy as well as the incremental risks posed by the intravitreal injection of triamcinolone. The additional risks are principally increased IOP, progression of cataract formation, and endophthalmitis. In the present study we have increased IOP in 2 patients in group B, both of which were controlled by medications and resolved completely in 34 months after treatment. Progression of cataract and endophthalmitis were not seen in our study group.

This study is limited by the small number of patients in each group with a limited follow ups. The physicians were not blinded during examination of the patients or FAG. The patients also knew they were in an experimental study. Therefore finding from this study should not be used as a justification to treat patients in an uncontrolled fashion. However in the course of development of new treatment strategies, the iteration starts with pilot series data that are used to formulate larger better controlled, but more expensive studies.

\section{Conclusion}

The findings from this study suggest that the combination of transpupillary thermotherapy along with intravitreal triamcinolone offers the possibility of better functional results than with TTT alone, meriting additional randomized study.

\section{Competing interests}

The author(s) declare that they have no competing interests.

\section{Authors' contributions}

RAR, JDR, LTB, TAM, JCL, GPO, RDJ, SMJ, and JFG have made substantial contributions to the conception, design, and acquisition of data together with data analysis and interpretation, and were involved in drafting the article and revising it critically for important intellectual content. HQM has given his final approval for that version to be published.

\section{References}

I. Ferris FL III, Fine SL, Hyman L: Age-related macular degeneration and blindness due to neovascular maculopathy. Arch Ophthalmol 1984, 12:1640-1642.

2. Macular Photocoagulation Study Group: Argon laser photocoagulation for senile macular degeneration: results of a randomized clinical trail. Arch Ophthalmol 1982, 100:912-918.

3. Macular Photocoagulation Study Group: Krypton laser photocoagulation for photocoagulation for neovascular lesions of age-related macular degeneration: results of a randomized clinical trial. Arch Ophthalmol 1990, 108:816-824.
4. Photodynamic therapy of subfoveal choroidal neovascularization in age-related macular degeneration with verteporfin: one year results of 2 randomized clinical trials-TAP report. Treatment of age related macular degeneration with photodynamic therapy (TAP) study group. Arch Ophthalmol 1999, I 1 7:1329-45.

5. Bressler NM: Photodynamic therapy of subfoveal choroidal neovascularization in age related macular degeneration with verteporfin: two year results of 2 randomized clinical trialsTAP report 2. Treatment of age related macular degeneration with photodynamic therapy (TAP) study group. Arch Ophthalmol 200I, II 9:198-207.

6. Verteporfin therapy of subfoveal choroidal neovascularization: two year results of a randomized clinical trial including lesions with occult with no classic choroidal neovascularization-verteporfin in photodynamic therapy report 2. Am J Ophthalmol 200I, | 31:54|-60.

7. Argon laser photocoagulation for neovascular maculopathy: Five year results from randomized clinical trials. Macular Photocoagulation Study Group. Arch Ophthalmol I99I, 109: I 109-14.

8. Laser photocoagulation of subfoveal neovascular lesions of age-related macular degeneration. Updated findings from two clinical trails. Macular Photocoagulation Study Group. Arch Ophthalmol 1993, III:120-9.

9. Margherio RR, Margherio AR, DeSantis ME: Laser treatments of photodynamic therapy and its potential impact on retinal practices. Retina 2000, 20:325-30.

10. Sharma S, Brown GC, Brown MM, Holland H, Shah GK: The cost effectiveness of photodynamic therapy for fellow eyes with subfoveal choroidal neovascularization secondary to agerelated macular degeneration. Ophthalmology 200I, 108:205I-9.

II. Vogi A, Birngruber R: Temperature profiles in human retina and choroid during laser coagulation with different wavelengths ranging from 514 to $810 \mathrm{~nm}$. Lasers Light Ophthalmol 1992, 5: |220-|23|.

12. Puliafito CA, Deutsch TF, Boll j, To K: Semiconductor laser endophotocoagulation of the retina. Arch Ophthalmol 1987 105:424-427.

13. Sheilds C, Sheilds J, Cater J: Transpupillary therapy for choroidal melanoma: tumor control and visual results in 100 consecutives cases. Ophthalmology 1998, 105:58I-590.

14. Reichel E, Berrocal AM, Ip M, Kroll AJ, Desai V, Duker JS, Puliafito CA: Transpupillary therapy of occult neovascularization in patients with age-related macular degeneration. Ophthalmology 1999, 106:1908-1914

15. Newsom RS, McAllister JC, Saeed M, McHugh JD: Transpupillary therapy for treatment of choroidal neovascularization. $\mathrm{Br}$ Ophthalmol 200I, 85: I73-I78.

16. Thach AB, Sipperley JO, Dugel PU, Sneed SR, Park DW, Cornelius J: Large-spot size transpupillary therapy for the treatment of occult choroidal neovascularization associated with agerelated macular degeneration. Arch Ophthalmol 2003, | 21:8|7-820.

17. Kumar A, Prakash G, Singh RP: Transpupillary therapy for idiopathic subfoveal choroidal neovascularization. Acta Ophthalmol Scand 2004, 82:205-208.

18. Killingsworth MC, Sarks JP, Sarks SH: Macrophages related to Bruch's membrane in age-related macular degeneration. Eye 1990, 4:613-21.

19. Dastgheib K, Green WR: Granulomatous reaction to Bruch's membrane in age-related macular degeneration. Arch Ophthalmol 1994, I I 2:813-8.

20. Oh H, Takagi $H$, Tagaki $C$, Suzuma $K$, Otani A, Ishida $K$, Matsumura $M$, Ogura $Y$, Honda $Y$ : The potential angiogenic role of macrophages in formation of choroidal neovascularization. Invest Ophthalmol Vis Sci 1999, 40:1891-8.

21. Kvanta A, Algvere PV, Berglin L, Seregard S: Subfoveal fibrovascular membranes in age-related macular degeneration expresses vascular endothelial growth factor. Invest Ophthalmol Vis Sci 1996, 37:1929-34.

22. Ishibashi T, Miki K, Sorgente N, Patterson R, Ryan SJ: Effects of intravitreal administration of steroids on experimental subretinal neovascularization in the subhuman primate. Arch Ophthalmol 1985, 103:708-II.

23. Antoszyk AN, Gottlieb JL, Machemer R, Hatchell DL: The effects of intravitreal triamcinolone acetonide on experimental pre- 
retinal neovascularization. Graefes Arch Clin Exp Ophthalmol I 993 , 23 I:34-40.

24. Okada N, Fushimi M, Nagata $Y$, Fukunaga $T$, Tsutsumi $Y$, Nakagawa $S$, Mayumi T: Evaluation of angiogenic inhibitors with an in vivo quantitative angiogenesis method using agarose microencapsulation and mouse hemoglobin enzyme-linked immunosorbent assay. Jpn J Cancer Res 1996, 87:952-7.

25. Danis RP, Bingaman DP, Yang Y, Ladd B: Inhibition of preretinal and optic nerve head neovascularization in pigs by intravitreal triamcinolone acetonide. Ophthalmol 1996, 103:2099-104.

26. Ciulla TA, Criswell MH, Danis RP, Hill TE: Intravitreal triamcinolone acetonide inhibits choroidal neovascularization in a laser-treated rat model. Arch Ophthalmol 200I, 199:399-404.

27. Tano $Y$, Chandler D, Machemer R: Treatment of intraocular proliferation with intravitreal injection of triamcinolone acetonide. Am J Ophthalmol 1980, 90:810-16.

28. Penfold PL, Gyory JF, Hunyor AB, Billson FA: Exudative macular degeneration and intravitreal triamcinolone. A pilot study. Aust N ZJ Ophthalmol 1995, 23:293-8.

29. Challa JK, Gillies MC, Penfold PL, Gyory JF, Hunyor AB, Billson FA Exudative macular degeneration and intravitreal triamcinolone: 18 months follow up. Aust N Z J Ophthalmol 1998, 26:277-8I.

30. Danis RP, Ciulla TA, Pratt LM, Anliker W: Intravitreal triamcinolone acetonide in exudative age-relate macular degeneration. Retina 2000, 20:244-50.

31. Chylack LT Jr, Leske MC, Khu P, McCarthy D, Wu SY: Strategies for measuring the rate of age-related cataract formation in vivo. Lens eye Toxic Res 1989, 6:515-50.

32. Schindler RH, Chandler D, Thresher R, Machemer R: The clearance of intravitreal triamcinolone acetonide. Am J Ophthalmol 1982, 93:415-7.

33. Scholes GN, O'Brien W], Abrams GW, Kubicek MF: Clearance of triamcinolone from vitreous. Arch Ophthalmol 1985, I03: I567-9.

\section{Pre-publication history}

The pre-publication history for this paper can be accessed here:

http://www.biomedcentral.com/1471-2415/5/27/prepub

\section{Publish with Bio Med Central and every scientist can read your work free of charge}

"BioMed Central will be the most significant development for disseminating the results of biomedical research in our lifetime. "

Sir Paul Nurse, Cancer Research UK

Your research papers will be:

- available free of charge to the entire biomedical community

- peer reviewed and published immediately upon acceptance

- cited in PubMed and archived on PubMed Central

- yours - you keep the copyright 